\title{
Combined Degrees - A New Paradigm in Engineering Education
}

\author{
David C. Shallcross and David G. Wood \\ Faculty of Engineering, University of Melbourne, Melbourne, Victoria 3010 \\ Australia
}

\begin{abstract}
Since the late 1980's undergraduate students in Australia have been able to enrol simultaneously in two full undergraduate programs. Students are able to complete their engineering degree while at the same time completing degrees in arts, commerce, law or science. Currently nearly $60 \%$ of all undergraduate engineering students at the University of Melbourne are enrolled in a combined degree program. By integrating the courses from the very first day of their studies students are able to complete their combined degrees in just five years for most combinations or six years for engineering and law. The engineering component of the combined degree programs is fully accredited with no core engineering material being lost. These combined degree programs provide a structural paradigm change in Engineering Education which enables significant flexibility in the undergraduate program and produces graduates having great appeal to employers. In addition the graduates have a wide range of skills and background which allow them to tackle the challenges of the future. For example consider the futures that await graduates with two full undergraduate degrees in chemical engineering and microbiology or civil engineering and geology. While demand for engineering courses have been falling away at many other institutions both within Australia and around the world demand for places in engineering combined degree programs has grown. The programs continue to attract students who might otherwise have been lost to other studies including commerce and law. In this paper the Combined Degree Programs at the University of Melbourne are described and its implementation discussed. The implications of the programs for the University, the profession and the wider community is discussed.
\end{abstract}

\section{Introduction}

Up until the 1990's the structures of the four-year undergraduate engineering degrees at the University of Melbourne were typical of most engineering degrees found around the world. They were very rigid. The subjects and the sequence in which they were to be studied were prescribed. All subjects were year long and a student who failed in one or more subjects were required to repeat the year. In their first year students studied the basic sciences of mathematics, chemistry and physics. They also received general engineering education across the major engineering disciplines. Then over the next three years they undertook studies in engineering science, practice and design. They also studied other subjects including economics, management and engineering law. 
Occasionally permission was given for students to undertake one or two non-engineering subjects allowing them to pursue some other interest. These subjects were taken either as extras in addition to their normal study loads (i.e., as an overload) or they were taken in lieu of certain specified subjects. If the student wished to complete two degrees then there was no alternative but to pursue them consecutively. Usually some credit was given towards the second degree for work performed in the first degree. For example, a student who had completed a three-year Bachelor of Science (BSc) degree might be given one year's credit towards a four-year Engineering (BE) degree. This would reduce the total time taken to obtain both undergraduate degrees from seven years to six years.

Beginning in the late 1980's students were permitted to enrol in two degree concurrently (i.e., simultaneously). By taking extra subjects in each semester and by spreading the content of both degrees over the entire time, it became possible for students to achieve a reduction in the time required to complete the requirements of both degrees. For example, instead of taking seven years to complete studies towards undergraduate degrees in both Engineering and Commerce, it became possible to gain both degrees in only five years. However the workload required to accomplish this feat was very heavy with overloads required in every semester. Only students with demonstrated abilities were permitted to enrol in concurrent degrees.

In 1989 the first combined degree program involving Engineering was introduced at the University of Melbourne. The combined Bachelor of Engineering/Bachelor of Science (BE/BSc) program was introduced and began to attract high achieving students into the program. The program's structure makes it possible to meet the requirements of both degrees in just five years. It should be noted however that it is not possible to obtain a BSc degree by simply studying for an additional year after completing the BE degree. Study for the two degrees must be integrated from the moment the student enters the University.

The Bachelor of Engineering/Bachelor of Arts (BE/BA) combined degree program was introduced in about 1992 allowing students to pursue an interest in a language, history or other arts major while undertaking the engineering degree. Like the Bachelor of Engineering/Bachelor of Commerce (BE/BCom) degree introduced later, the BE/BA combined degree program requires five years of study. The combined degree program in Engineering and Law (BE/LLB) requires six years of full time study.

The reduction in the time required to complete the two degrees is achieved in part by the existence of material common to both degrees. This is particularly true for the BE/BSc program in which a sound understanding of mathematics, physics and/or chemistry is important to both degrees. But for the BE/BA program the overlap in material is less obvious.

\section{An Overhaul for Engineering Education}

The introduction of the combined degree programs in Engineering and other degree programs at the University forced academics across the University to look carefully at their courses and at the material they teach. Year long and so-called omnibus subjects were eliminated and replaced by unitized and semesterized subject units. The notions of the year level and passing by years have also gone.

With very few exceptions now all students, no matter what their degree program, enrol in four equally-weighted subjects each semester. No longer can the academic in charge of a subject be 
completely sure which other subjects her or his students are currently enrolled in. A class in, for example, a 300-level (formerly third year) civil engineering subject may consist of students enrolled in several programs. They may be taking subjects outside of engineering, or from across the different year levels within civil engineering. The class will contain single degree students who are also undertaking other 300-level engineering subjects. It may also contain combined degree students who are also enrolled in either some 200-level or 400-level subjects. This means that the material covered in an engineering subject or unit must be as self-contained as possible with all pre- and co-requistites carefully managed.

In some countries the duration of university courses was 3 years post school whereas in Australia all university engineering programs have had a duration of 4 years from the very beginning of higher education in the country. Indeed the very first Engineering degree courses taught at the University of Melbourne in 1882 consisted of 3 years of an arts course followed by 1 year of "rigorous" engineering. Maybe this could be regarded as the very first Combined Degree program!

Today it has been universally accepted that for professional engineering education a taught course of four years is considered appropriate. Occasionally there is a call for a fifth year to be introduced because it is recognised that new developments cannot be fitted into the standard curriculum. In many countries governments are responsible for a major share of the cost of university education and hence there is strong government resistance for increasing the course duration.

An examination of typical engineering undergraduate courses in a number of countries suggests that the formal workload as described by the number of "contact hours" is excessive, particularly when compared to other undergraduate degree programs. Engineering academics are the first to say that a large number of contact hours is necessary because of the prescribed course content deemed to be essential for professional recognition. We strongly believe that this is not true. It has become necessary to carefully examine everything taught in our engineering courses. We have come to a position in university engineering education where we can no longer continue adding to course loads without recognising that it is not important to teach everything that we once thought was important for an engineer to know. Some "sacred cows" must be sacrificed. We believe however that any engineering material lost in the education of combined degree students is more than made up by the increased breadth brought to their education by the second degree.

At the same time that the engineering subjects were being reshaped into stand-alone semesterised subjects the same was happening across most of the rest of the Universities. Subjects in Architecture, Arts, Economics and Commerce, Education, Law, Music and Science were also reshaped opening up the possibilities of a wide range of combined degree opportunities. Other combined degree offerings currently available including Science/Arts, Science/Commerce, Science/Law, Commerce/Law and Arts/Education. Combined degree programs currently being planned include Engineering/Education and Engineering/Music.

\section{Combined Degree Programs}

The Faculty of Engineering at the University of Melbourne offers degree programs in Chemical, Civil, Computer, Electrical, Environmental, Geomatics, Mechanical and Software Engineering as well as a three year degree program in Computer Science. In 2001 the Faculty of Engineering at 
the University of Melbourne had approximately 4000 undergraduate students. Figure 1 shows that the total number of undergraduate enrolments nearly doubled between 1994 and 1999. This occurred despite the fact that across Australia at that time there was a move away from studying engineering. The growth in numbers is largely due to the growth in combined degree enrolments.

Figure 2 shows the number of students in the final year of their degree programs across all engineering streams. Here we see that the number of students in the final years of their courses more than doubled between 1994 and 2001. During this time however the number of students enrolled in the single degree programs has remained relatively unchanged.

The proportion of students enrolled in the single and combined degree programs varies considerably across the engineering disciplines. In $200172.9 \%$ of environmental engineering students in the final year of their course were in combined degree programs while the corresponding figure for mechanical engineering was $44.8 \%$. Figure 3 presents the numbers of students in the final year of their programs for each of the engineering disciplines in 2001. The changes in student enrolments over time are presented for Mechanical Engineering in Figure 4 and for Chemical Engineering in Figure 5. In Mechanical Engineering strong growth has been seen in all degree programs while over the same period in Chemical Engineering the growth in the combined degree programs has offset the decline in numbers in the single degree program.

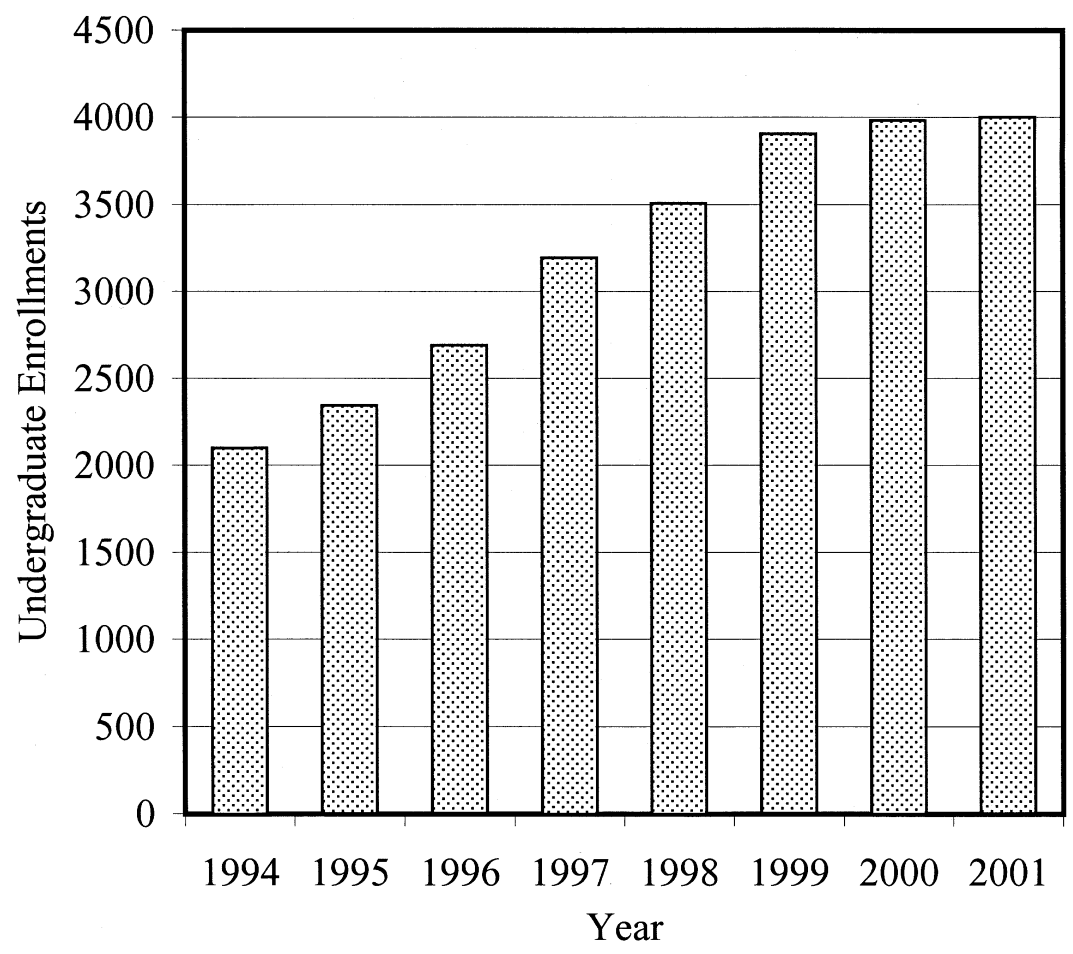

Figure 1 : Total undergraduate enrolments in the Faculty of Engineering. (Figures include Computer Science students). 


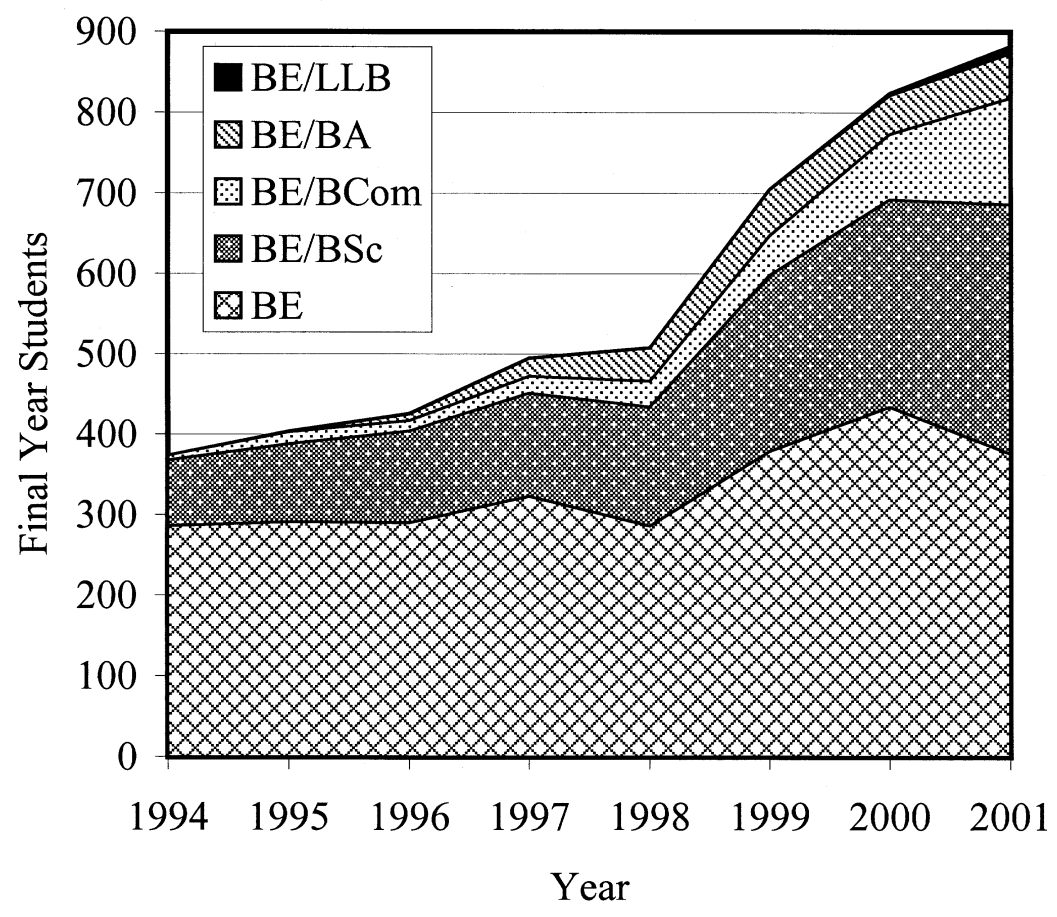

Figure 2 : Numbers of students in their final year of their degree programs.

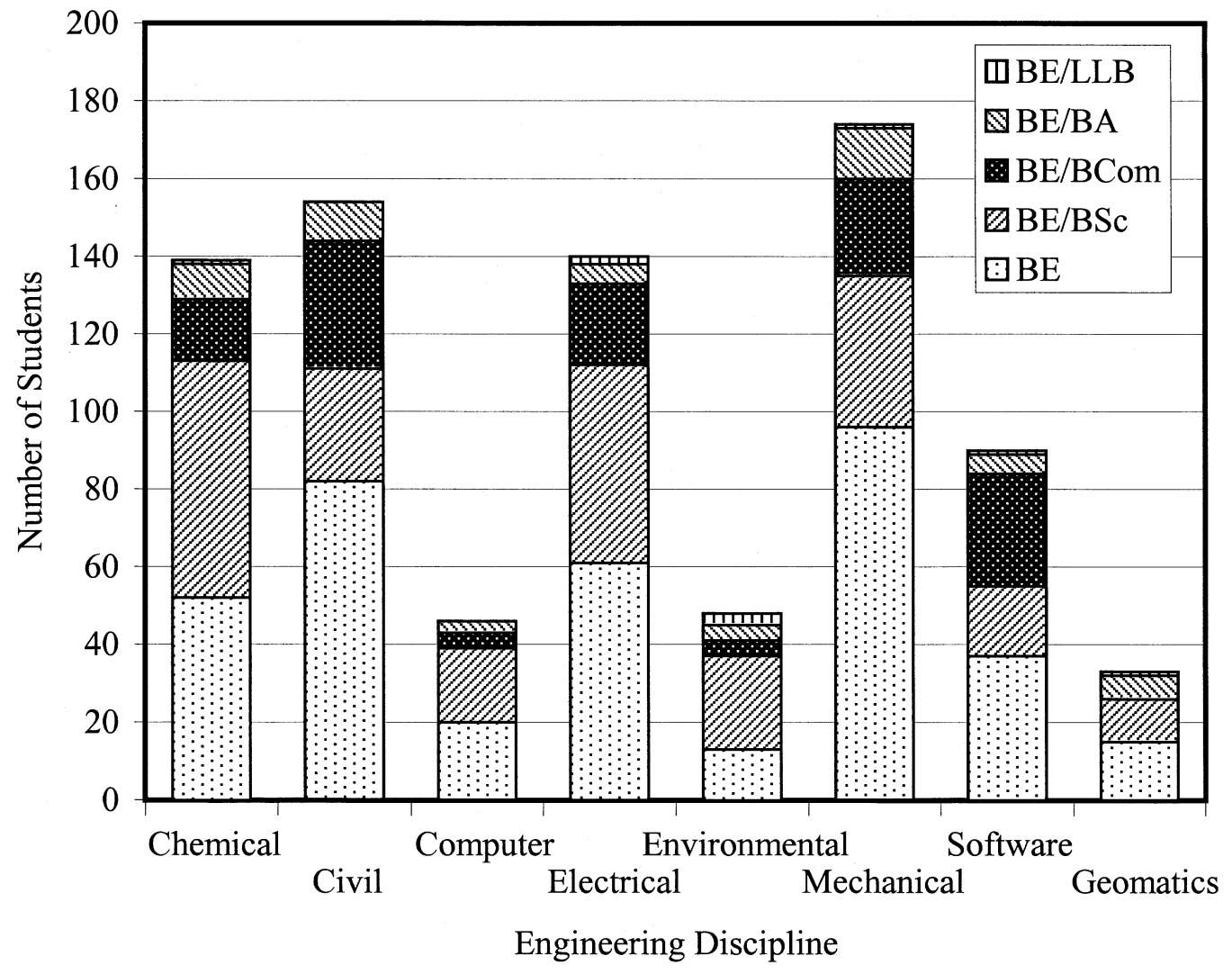

Figure 3 : Numbers of students in their final year of their degree programs for each of the engineering disciplines taught. Data for 2001. 


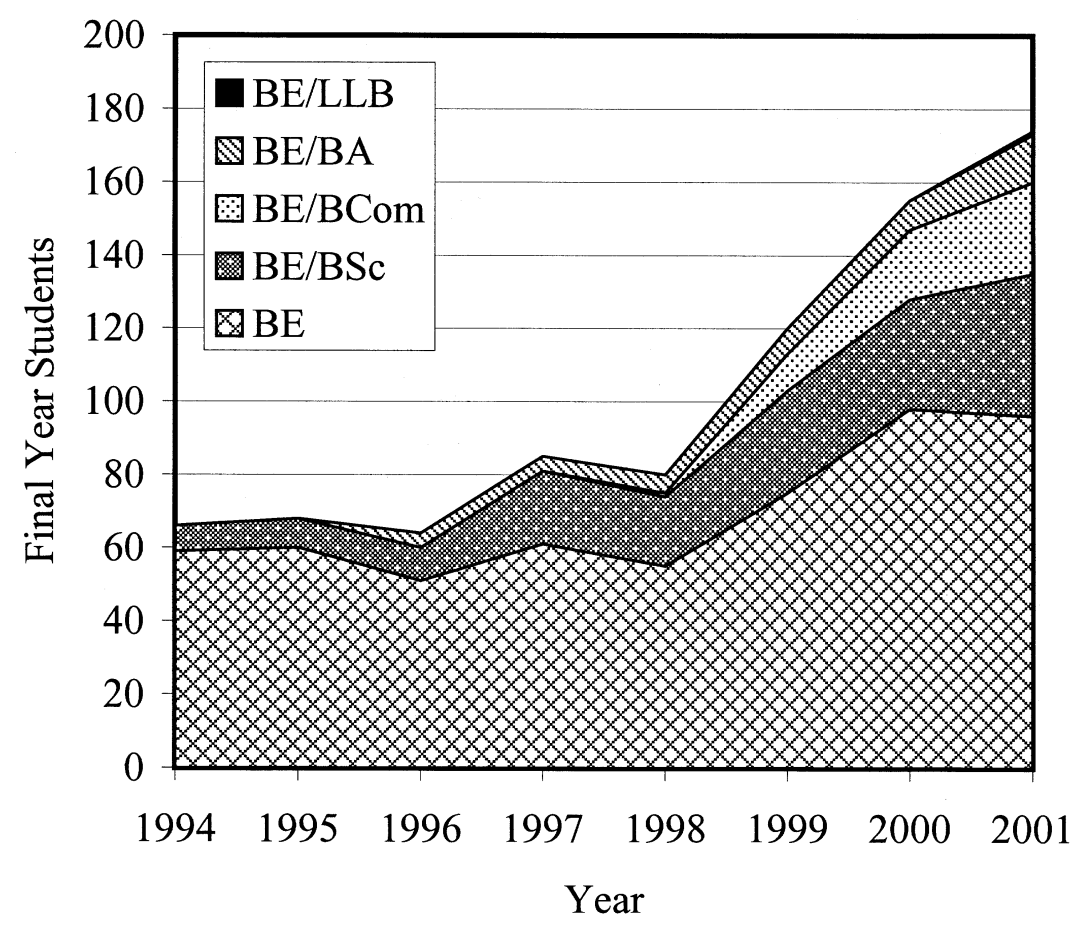

Figure 4 : Numbers of students in the final year of their mechanical engineering degree programs.

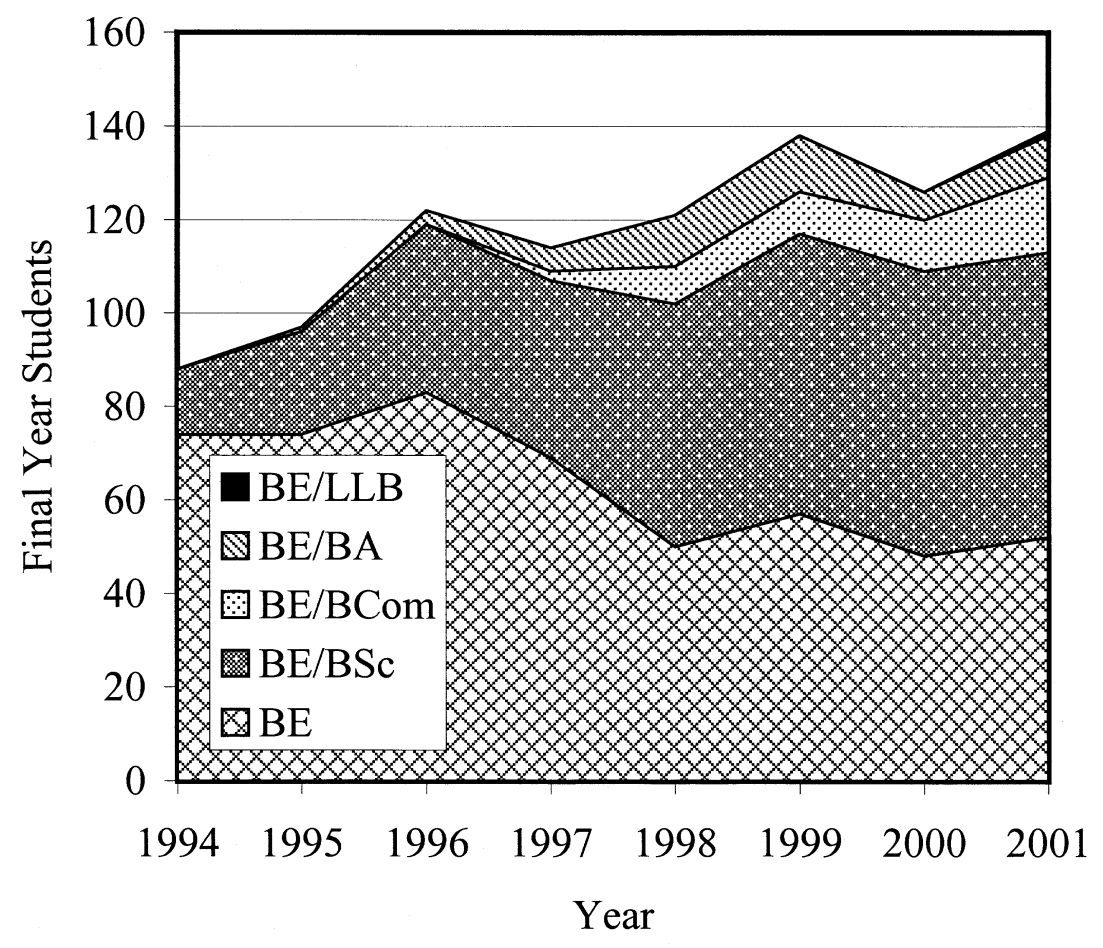

Figure 5 : Numbers of students in the final year of their chemical engineering degree programs. 


\section{Student Perspectives}

Students give many reasons for their decisions to undertake study in a combined degree program. Some of these are based upon fact and others on perceptions.

1) There is a general perception among many prospective and current students that a second degree will enhance their career prospects. Many students feel that a second degree will permit them to apply for a greater range of jobs outside one narrow profession. Many feel that prospective employers will favour graduates who have completed diverse studies. While this is true in some cases, in others a second non-engineering degree is of little relevance to prospective employers.

2) When the times comes to select a course to undertake at university many students are uncertain as to the career they wish to pursue. By enrolling in one of the combined degree programs the students are able to get a better appreciation of what is involved in more than one career. After two or three years of the program some students drop one or other of their degrees to concentrate on their preferred course.

3) Some students know that they want an engineering degree but at the same time they want to pursue subjects of special interest to them. This is particularly true of those students who wish to continue to study a language. Enrolling in a combined degree program allows them to maintain an interest in a non-technical discipline why still studying towards an engineering degree. They enjoy the flexibility in subject choice allowed by enrolling in the non-engineering programs.

4) The scores required to gain admission to the combined degree programs are higher than those to gain admission to engineering alone. Some high-achieving school students elect to undertake a combined degree because it is more difficult to gain admission, and is considered by some to be more prestigious than a single engineering degree.

\section{A Diverse Range of Programs}

Since its introduction the BE/BSc program has been the most popular of all combined degree programs. The science majors favoured by students vary between engineering disciplines. Not surprisingly chemistry has proven to be the most popular science major amongst the chemical engineering students as many see it as the natural complement to their engineering studies. For electrical engineering physics is the top ranked science major while for civil engineering geology is favoured.

The distribution of science majors amongst $\mathrm{BE} / \mathrm{BSc}$ chemical engineering students is presented in Figure 6. After chemistry, the biological sciences which include biochemistry, genetics, microbiology and pharmacology are the most popular major. Other science disciplines combined degree students have enrolled in include botany, geology, psychology and zoology.

Of the BE/BA students enrolling over the same period about three-quarters undertake a language as their Arts major. Other majors include criminology, fine arts, history, linguistics, politics, psychology and women's studies. The diverse nature of studies combined students undertake is indicative of the flexibility of these programs. 


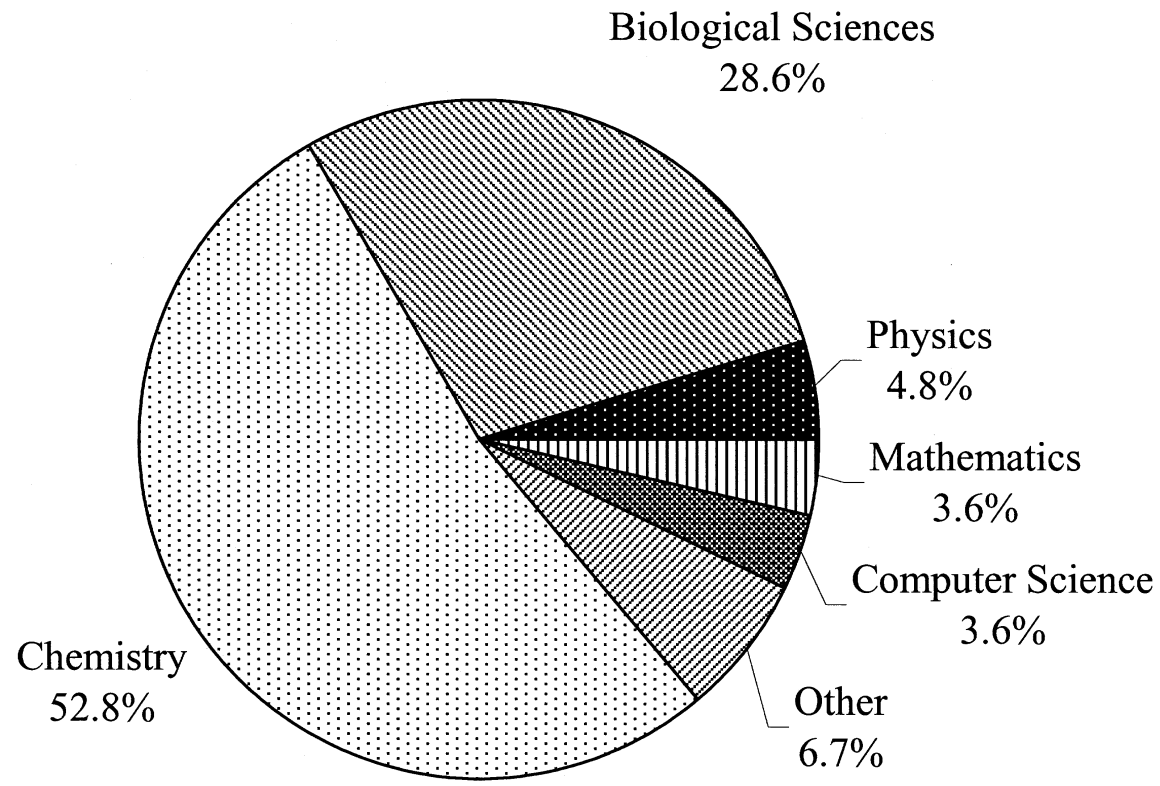

Figure 6 : Distribution of science majors for chemical engineering students enrolled in BE/BSc combined degree programs.

\section{Intellectual Stimulation}

Many combined degree students state that they often find the non-engineering subjects of their courses to be more intellectually stimulating. This may be because they are able to select the subjects they wish to study in their non-engineering degree. For example, a BE/BSc student studying physics is able to select subjects that relate to those aspects of physics that relate to their specific interests, be they astrophysics, electromagnetism, optics or nuclear physics.

Some students find the engineering and non-engineering material to be equally stimulating but in different ways. Some feel that they exercise different sides of their brain when they move between the engineering and non-engineering subjects.

\section{A Paradigm Shift in Engineering Education}

As formal chemical engineering education celebrates its first one hundred years let us consider how it has evolved over that time. In his plenary lecture at the Asia Pacific Confederation of Chemical Engineering Congress in Seoul, South Korea in 1999, Professor James Wei described the traditional paradigms of chemical engineering education ${ }^{1}$.

The first chemical engineering curricula developed were more applied indus trial chemistry than what we know today as chemical engineering. Students studied existing processes but not the underlying design principles necessary to propose, design, develop and operate new processes. The first steps to introduce a more thorough understanding of these principles were taken in 1915 when Arthur D. Little, an advisor to the chemical engineering course at MIT, recommended that the core material should be centred on unit operations ${ }^{1}$. These unit operations included the major industrially-important processes such as heat transfer, distillation, fluid flow and filtration. The study of unit operations revolutionized chemical engineering education. In 1923 Walker, Lewis and McAdams published their book, 'Chemical Engineering Principles' which went on to become one of the major landmarks in chemical engineering education. This simultaneous shift 
and focussing of emphasis in education is often considered the First Paradigm of Chemical Engineering Education. For the first time chemical engineers were armed with a set of tools to allow them to design more efficient processes and systems. Many students saw this as the distinguishing feature of chemical engineering because at the time the chemists were still teaching courses in reactors for chemical engineers as a combination of chemical kinetics and chemical thermodynamics.

Some forty years later the publication of 'Transport Phenomena' written by Bird, Stewart and Lightfoot ushered in the Second Paradigm of Chemical Engineering Education. Again a revolution in chemical engineering education occurred. By mathematically modelling the processes of momentum, heat and mass transfer greater insights into processes were gained. It now became possible to simulate entire processes, allowing students to model and predict process performance with varying degrees of confidence. The use of the fundamental equations of change for the teaching of momentum, heat and mass transfer was seen to be too mathematical by a number of chemical engineering departments . It was in fact the first method of teaching that gave a strong sense of logic to key dimensionless numbers such as Reynolds number. These numbers and their physical meaning simply evolve from the dimensionless equations of change. Also at this time came Octave Levenspiel's classical text on Chemical Reactor Engineering which led to excellent programs in Reactor Engineering taught by chemical engineers.

Now another forty years later the chemical engineering education community is looking for the Third Paradigm, which like the other two will revolutionize chemical engineering education. Wei suggested several different possibilities for this Third Paradigm which will empower engineering graduates to meet the challenges of the new century.

- Should chemical engineering become more oriented towards perceived societal needs such as environmental protection and sustainability?

- Should it move to embrace developing disciplines as exemplified by information technology, nanomaterials and tissue engineering?

- Should the education processes focus more on people, teamwork, leadership and communication skills?

- Should it broaden to more hybrid degrees of financial engineering ?

- Or should chemical engineering education focus not so much on the design of new processes but more on the development of new products?

Wei in his "search" for the third paradigm suggests Product Engineering, Bioengineering, Tissue Engineering and a number of others. He refers to "content paradigms" whereas what is needed is a structural paradigm shift to provide for the many new areas of chemical engineering

Leaders of the chemical engineering profession such as former AIChE Preident Calvin Cobb have also questioned the future direction of the chemical engineering profession ${ }^{2}$. Will chemical engineering break apart completely, devolving into discrete specialisations related to areas such as biotechnology or nanotechnology?

As in any industry chemical engineering educators must also consider the demands of their clients, namely their students the processing industries and the chemical engineering profession. In the last two decades of the 20th century the petrochemical industries, traditional employers of chemical engineering graduates reduced their graduate recruitment programs. In order to find employment graduates began to consider the opportunities in non-traditional industries such as 
food, financial and pharmaceuticals. Can the search for the Third Paradigm and the changing requirements of the clients be answered in a single development?

We believe that while no single degree can produce a graduate with all the attributes Wei suggests, the combined degree programs at the University of Melbourne do produce graduates who between them meet all the challenges raised by Wei. Some graduates, with second degrees in fields such as botany, chemistry or economics will be able to address societal needs such as environmental protection, and sustainability. Other graduates with second degrees in computer science, physics, genetics or microbiology will be in positions to embrace developing disciplines as exemplified by information technology, nanomaterials and tissue engineering. Combined engineering/arts and engineering/commerce graduates have excellent teamwork, leadership and communication skills. Combined degrees of chemical engineering and commerce are the hybrid degrees suggested by Wei and others. And who are better placed to develop new products than engineers who hold second degrees such as biochemistry, microbiology, pharmacology or physics?

We suggest that the combined degree programs offered for engineering students at some Australian universities, including the University of Melbourne, offer a structural paradigm shift which enables students to select from a significant number of options and yet preserve a core of chemical engineering which yields professional accreditation. This structural paradigm does not just apply to chemical engineering students but rather to engineering students across all engineering disciplines.

We propose that these combined degree program offer a structural paradigm for engineering studies which enables a flexibility of content to be achieved whilst maintaining the appropriate accreditation of the BE degree. It is attractive to school students and the graduates are eagerly sought by employers. While it does involve a further year of study at university and the Australian Government which is not known for its interest in providing funds for higher education approves the program for funding purposes.

\section{Concluding Remarks}

The introduction of the combined degree programs within Australian universities in the early 1990's as typified by those at the University of Melbourne has been an unqualified success. The programs allow students to pursue their interests while studying for their engineering degrees. At the same time industry has welcomed graduates with diverse and broad-based knowledge and skills.

In the mid-1980's research into the preferences of school leavers showed that they were strongly influenced by parents who wanted their sons and daughters to take "Business studies" and hence make a lot of money. School teachers were also encouraging this type of enrolment because they had no knowledge of engineering. The majority of students getting this advice had studied maths, physics and chemistry at school each of which being essential for Engineering entry. The majority of female school leavers wanted to study something connected to biological studies.

The combined degrees enabled students to heed the advice of the parents and teachers but to keep their options open and also take Engineering. This "experiment" worked with great and rapid success. High quality enrolments rose rapidly and the number of females studying towards 
engineering degrees rose to an all time high of $28 \%$ within the Faculty and to $50 \%$ within the chemical engineering and environmental engineering courses.

In broadening the education of our engineering students we must still ensure that the fundamental elements of engineering education are retained. We support the views of Cobb who stresses that educators should continue to build upon the strengths of the profession in problem synthesis and a systems approach to problem-solving.

Our research shows that the combined degree programs have attracted students into engineering who would otherwise not have enrolled. The combined degree program is now well established at the University of Melbourne and is a success.

\section{Reference}

1 Wei J., 'The Third Paradigm : For the Millenium', Proceedings of the 8th APCChE Congress, Seoul, Korea, August 1999, p 1

2 Cobb C.B., 'Prepare for a Different Future!', Chemical Engineering Progress, 97(2), 2001, p69-74

\section{Biographical Information}

DAVID C. SHALLCROSS is an Associate Professor in the Department of Chemical Engineering at the University of Melbourne. He is also Associate Dean of the Faculty of Engineering. He has won several teaching awards and in 1999 became the first engineering academic to receive the University's highest teaching award, the Universitas Fellowship.

DAVID G. WOOD is Professor and Dean of Engineering at the University of Melbourne. He was Chair of the Department of Chemical Engineering at the University from 1982 until 1996. In 2001 he was awarded the Chemeca Medal, the highest award bestowed on professional chemical engineers in Australia and New Zealand. 